\title{
Concerning Web-based e-learning at a Maritime Higher Education Institution: Case Study
}

\author{
Sanja Bauk, Roland Radlinger
}

The purpose of this article is threefold. Firstly, it considers the real needs which led to the idea of conceiving and developing new study program supported by web-based e-learning system (WELS) at the Faculty of Maritime Studies (University of Montenegro) as maritime higher education and training institution. In this part of the article the collaborative projects which enhanced this idea and its implementation are described briefly, as well. Secondly, the results of the polls realized among certain number of involved students, teachers, and experts in related activities, are presented and discussed in order to identify main features along with pros and cons of the WELS being here examined. And, thirdly, some empirically based suggestions when it comes to choose the appropriate software tools for creating more interesting, engaging, inciting, and thus of higher quality instructional materials being available through WELS, are given.

\section{KEY WORDS:}

$\sim$ Web-based e-learning system (WELS)

$\sim$ Maritime higher education

$\sim$ Audio, video and screen recording software tools selection

Faculty of Maritime Studies - Kotor, University of Montenegro, Montenegro e-mail: bsanjaster@gmail.com

a. Academy of New Media \& Knowledge Transfer, University of Graz, Austria

\section{INTRODUCTION}

Nowadays, numerous recognized and respectful maritime educational and/or training institutions and companies offer e-learning courses, like: Lloyd's Maritime Academy, Maritime and Coastguard Agency, MPI Group, USCG Maritime Institute, etc. Of, course the list is long and should not be limited to the above given one. Also, there are a considerable number of scholars' analyses that support the concept of web based e-learning as additional mode of acquiring/transferring knowledge and skills, not only in maritime education, but in general ( $\mathrm{Ng}$ et al., 2009; Bauk et al., 2012; Buzađija, 2011; Flatcher and Dodds, 2003; Hanzu-Pazaraet al., 2010; Kadioglu, 2008). However, like in the previous case, the readers should not be limited to these quotations. What supports additionally using WELS at maritime higher educational institutions is the document "The Manila Amendments to the Standards of Training, Certification and Watch-keeping for Seafarers Convention and Code" (Philippines, 21-25 June 2010), which concerns, among other numerous issues: $<<$ the introduction of modern training methodology including distance learning and web-based learning into maritime education and training $>>$. This strongly supports the efforts of conceiving, implementing and developing WELS at maritime higher educational and/or training institutions.

\section{BACKGROUND}

The Faculty of Maritime Studies of Kotor (FMS) has long lasting tradition being founded even in the medieval times, when captain Marko Martinović had his own nautical school for 
Russian feudal lords (in 17th century) in Perast, a little seaside town near Kotor (today Montenegro). Later on, this nautical school continues to exist in Kotor, and it still works as FMS, educating students and seamen for a variety of both ship and port vacancies. Also, graduated students can find employment in the agencies and companies which are focused on different maritime affairs. Although the tradition of nautical and maritime studies in general is a long-lasting and rich one in Kotor, and along the whole Montenegrin littoral zone, the awareness of the existing new and demanding requirements of the actual global living and working flows is necessary. Above all, this awareness is unavoidable since the situation in Montenegro, in the sphere of maritime affairs, is not a flourishing one. Accordingly, the management of the FMS has recently come up to the idea of introducing web-based e-learning environment for the needs of the students, especially seamen among them, and all other persons being interested in this mode of education and knowledge transfer. It is to be mentioned in this context that FMS several years ago, was forced in a way to adapt the curricula to the Bologna system which recommends, among other things, presence of the students at almost all classes during the semester. Thus, if the students are not present, or if they are usually absent from their classes, there is a risk that they will not pass the examinations! This is particularly the case with the students who have to sail, i.e. to work as seamen to earn their salaries, and to study simultaneously. During the past few years, there were numerous requirements from their side to the FMS's management to organize for them condensed courses several times a year, or to develop and offer them e-learning educational modules. Consequently, the FMS's management decided to meet their requirements and objective needs, and to develop and implement an appropriate web-based e-learning study program.

\section{PERPETUATORS}

What caused developing e-learning instructional modules at the Faculty of Maritime Studies (FMS), University of Montenegro, besides the enthusiasm of a few teachers and their desire to enrich traditional channels of knowledge transfer, are three projects briefly presented below.

Project 1: The first one is the Tempus project (2010-2013): "Enhancing the quality of distance learning at Western Balkan higher education institutions" (Enhancing the quality of distance learning at Western Balkan higher education institutions, 2013). The objectives of this project are: to improve the quality and relevance of distance education at Western Balkan higher education institutions and to enable easier inclusion of partner country institutions into European Higher Education Area. This implies the specific objectives: to improve, develop and implement accreditation standards, guidelines and procedures for quality assurance of distance education study programs according to EU practices at national level in Western Balkan (WB) beneficiary countries; to establish the framework for improving distance learning (DL) quality assurance and e-learning methodology on higher education (HE) institutional level in WB countries; to provide training for relevant members of $\mathrm{HE}$ educational and public authorities responsible for accreditation and evaluation of DL programs and trainers involved in DL from each partner country, etc. The project leader is University of Kragujevac (Serbia). Owing to this large project, University of Montenegro Center of Information System "set up" Moodle (1.94) server, that creates the opportunity for FMS to use its capacities in preparing and realizing web based educational activities. Through this project a few teachers and assistants from FMS also had opportunities to attend short training courses being dedicated to e-learning several times and to participate in discussion process along with the experts from EU in this domain.

Project 2: The second is the small project of bilateral cooperation realized between FMS and the Academy for New Media and Knowledge Transfer - ANMKT (University of Graz). This project entitled "Developing an e-learning module at Faculty of Maritime Studies (Kotor, Montenegro) for the seamen educational needs" had as its main aim conceiving a new webbased educational program at FMS devoted primarily to the seamen's (among the students) needs. However, this module should be used by all other potential users besides seamen who are interested in such a kind of acquiring knowledge. The University of Graz supported the project by bringing in perennial expert knowledge in novel e-based didactical methods and techniques. In return developed e-learning methods and tools were tested on the basis of a concrete case study. Within this project (2011-2013) experts from ANMKT transferred very useful practical skills on the use of Moodle Management Learning System (MLS) in the effective implementation of e-learning to the teachers and system engineers of FMS throughout several trainings.

Project 3: The third important project within this context is a follow-up of the previously mentioned project of bilateral cooperation between FMS and ANMKT. This project entitled "Distant learning implementation at the Faculty of Maritime Studies, University of Montenegro, as an additional mode of education" aims at effective implementing and developing of web-based e-learning at the FMS as an additional mode of knowledge transfer, devoted again primarily to seamen's needs. ANMKT was the partner in conceiving this e-based instructional module and through this project it would support its effective implementation. In the mean time, this e-learning module has been accredited by the Montenegrin National Council for High Education, and the study program started officially in September, 2012. This e-learning module is still implemented by Moodle platform, and currently it is available at the FMS web portal fzp.moodle.ac.me/login/index.php. The materials for some of 


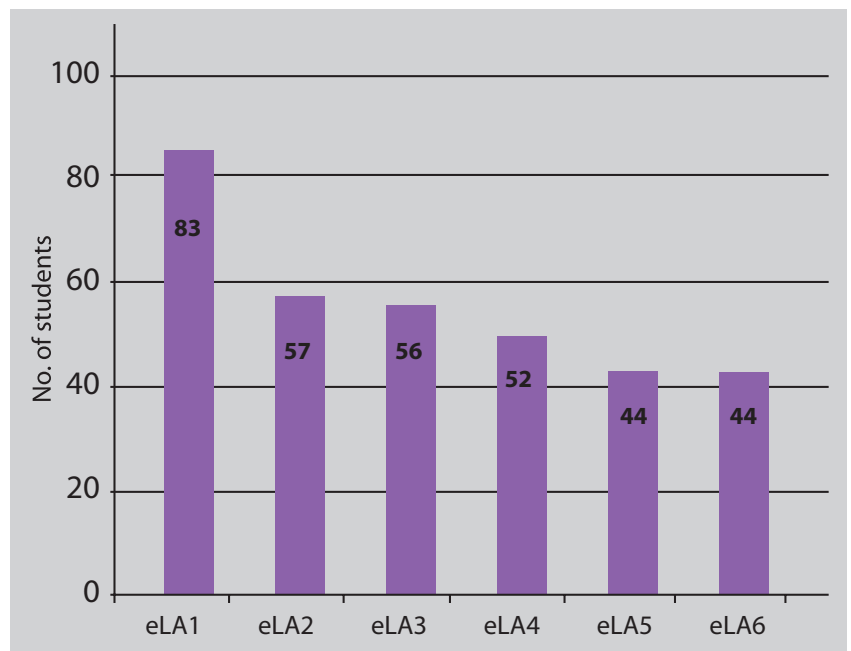

Figure 1.

Number of e-learners who opted for the offered WELS advantages (Table 1).

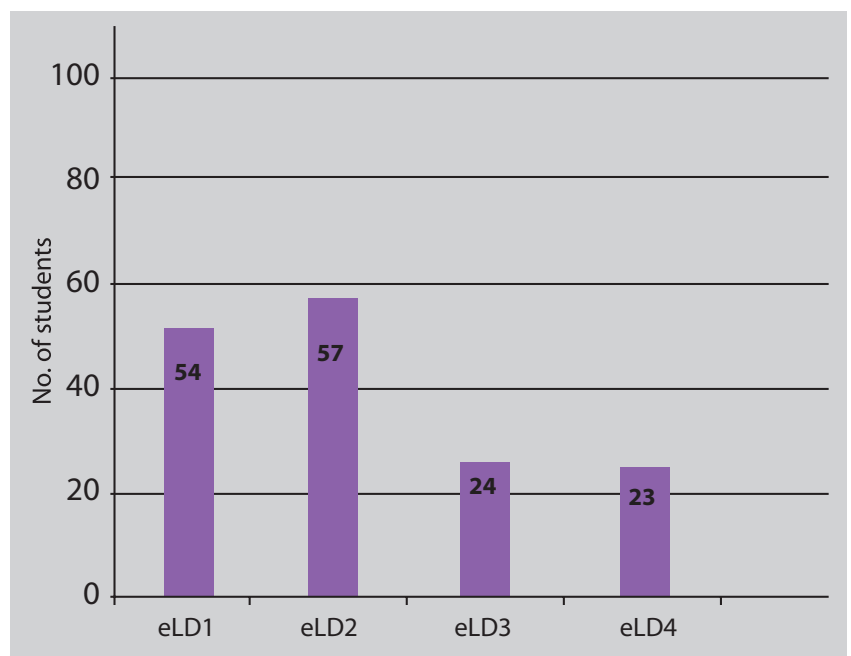

Figure 2

Number of e-learners who opted for the offered WELS disadvantages (Table 1).

In order to obtain as complete as possible a feedback in the current moment on the realized WELS, besides the surveys among the students of the specialist studies at the FMS, one survey is conducted among teachers at the FMS and experts in developing new IT-supported didactic methods from the ANMKT. The poll conducted among the teachers and the experts has been based on the well-known and in literature extensively used Saaty's AHP
(Analytical Hierarchy Process) method and the author's previous research papers (Bauk et al., 2013a; Bauk et al, 2012). This approach enabled us to rank some WELS features, which have been in the context of this study identified as important ones (Table 2). The ranks are determined by the values of normalized average weight coefficients being previously calculated for each considered criteria, i.e. WELS feature. Certainly, the readers should not be limited by them in the sense that the need for further, more extensive and rigorous research in this area is underlined.

Table 2 .

The rank of the analyzed WELS features by AHP approach on the basis of the survey among experts (ANMKT) and teachers (FMS).

\section{Feature \\ Rank}

Availability on-line and high quality of all necessary materials for preparing the exam in a subject

Stability and speed of the Internet connection (that is not always the case at sea and in some ports)

The existence of the tests for selfevaluation of the acquired knowledge

Possibility of regular communication with teachers via forum, chat and/or e-mail

Possibilities of doing and evaluating tests and final exam on-line

Conducting regular students' surveys

The obtained grades in the analyzed WELS features could be qualified in the following manner:

- The teachers and experts involved in this research assigned numerically the highest marks, and gave consequently the greatest importance in the qualitative sense to the availability on the web of the instructional materials (which implies their appropriateness and quality);

- In the second place they put the stability of Internet connection, which is understandable since the WELS examined here is devoted mostly to the seafarers. Namely, it is often not possible to establish Internet connection on the vast sea, or it is usually unstable. Another interpretation should be that the teachers and the experts consider a stable Internet connection fundamental prerequisite for WELS establishing;

- In the third position there is the availability of tests for students' (here mostly seafarers') self-evaluation during the process of acquiring knowledge that is also a very important segment of e-learning which indirectly should involve the existence of smart educational games as well; 
- The fourth position is assigned here to the possibilities for the students to communicate to teachers via forum, chat, e-mail, etc. which is of course a very important segment of e-learning, but it is sometimes difficult to achieve this due to the previously mentioned problems with Internet connection and its stability at sea (and sometimes in ports). On the other hand, teachers are usually too busy, and they are practically sometimes physically unable to devote more time to the communication with students;

- At the lowest positions are WELS technical possibilities of doing exams on-line, and conducting regular on-line (or classical) surveys among students related to their degree of satisfaction with offered e-learning services respectively. This is understandable since the Internet as an open communication channel is not perfect for testing students on-line. In addition, even surveys conducted among students are very important. In comparison with the previously considered components of e-learning they are for sure slightly less important. However, this does not mean at all that they should be ignored.

This conducted survey reflects profoundly very subtle nuances in mutual positions of the analyzed e-learning features, and it reminds us to associate them to the high degree of expertise and sensitivity of the responders in this domain (Bauk et al., 2013a).

Further analysis should be directed toward evaluating e-learners' satisfaction with offered WELS and this will be realized by multi-criteria evaluation technique based on Saaty's AHP (Paechter et al., 2010; Shee and Wang, 2008; Wang, 2003). Since the large number of respondents is necessary for conducting such analysis, the possibility of involving some other institutions that offer WELS is in consideration. Namely, a large number of respondents is a kind of guarantee that the survey will be successful and reliable, i.e. that the largest number of respondents will be consistent in accordance to the Saay's AHP method requirements.

\section{TECHNICAL SUPPORT: CHOOSING APPROPRIATE SOFTWARE TOOLS FOR CREATING INCITING INSTRUCTIONAL MATERIALS}

If we look at the above presented ranking of the WELS features, it is evident that the availability and quality of the instructional materials are rated as the most important factors by teachers and experts in WELS. Undoubtedly, the quality of the instructional material is one of the key factors for successful implementation of WELS. Since the appropriate IS/IT solutions and tools are necessary in their creating, this part of the paper offers a short overview of some available up-to-date software tools for creating interesting and engaging instructional WELS materials, along with the recommendations based mostly on the authors' experience which of them is the most appropriate for certain application.
Today, there is quite a large offer of different proprietary commercial and freeware application software which can be used for producing (Table 3):

- Audio: Audacity, NCH Wave Pod, Adobe Audition, Cubase Steinberg, Logic Studio, Kristal Audio Engine, etc.;

- Video: Windows Movie Maker, Adobe Premiere, Avidemux, Magix Video, Video Spin, AVledit, etc.; and,

- Screen capturing: Adobe Capticate, Capture Fox, Camtasia Studio, Jing, ActivePresenter, BB Flashback, BB Flashback Express, ScreenPresso, VirtualDub, etc.

Web can be used as a resource for further search (Best Free Audio Editing Software, 2013; Best Free Video Editing Software, 2013).

Table 3.

List of the software tools for post-production of e-learning teaching materials.

Legend: A-audio; V-video; S-screen capturing;

C-commercial; F-freeware.

\begin{tabular}{|c|c|c|c|c|c|}
\hline Software / Feature & A & $\mathbf{v}$ & $\mathbf{S}$ & C & $\mathbf{F}$ \\
\hline Audacity & $x$ & & & & $x$ \\
\hline NCH Wave Pod & $x$ & & & & $\mathrm{X}$ \\
\hline Cubase Steinberg & $x$ & & & $x$ & \\
\hline Logic Studio & $x$ & & & $x$ & \\
\hline Kristal Audio Engine & $x$ & & & & $x$ \\
\hline Windows Movie Maker & & $x$ & & & $x$ \\
\hline Lightworks & & $\mathrm{X}$ & & & $\mathrm{X}$ \\
\hline Avidemux & & $x$ & & & $\mathrm{X}$ \\
\hline Magix Video & & $\mathrm{X}$ & & $\mathrm{X}$ & \\
\hline Adobe Premiere & & $x$ & & $x$ & \\
\hline Video Spin & & $x$ & & & $x$ \\
\hline AVledit & & $x$ & & & $\mathrm{X}$ \\
\hline Adobe Captivate & & & $x$ & $x$ & \\
\hline Camtasia Studio & & & $x$ & $x$ & \\
\hline Jing & & & $x$ & & $x$ \\
\hline CamStudio & & & $x$ & & $x$ \\
\hline
\end{tabular}

The list above is not exhaustive as there are many more software tools on the market, proprietary commercial as well as freeware and shareware. Of course, there is also difference concerning the available functions but it is definitely possible to produce up to professional results with selected freeware software.

The following recommendations can be done according to the authors' experiences: 
- The open source software Audacity is the most powerful freeware tool for audio editing. It offers various effects and analyzing tools for signal processing, e.g. powerful noise reduction (even adaptive noise reduction) and dynamic processing as well as equalizing, multi-track editing for sophisticated mixes and of course supports recording from any microphone or signal source connected to the computer. Professional commercial audio editing software mainly aims at professionals like sound engineers or sound designers. These professional tools provide further interfaces to audio hardware and various 3rd party plugins for high-end audio editing.

- In the field of video editing it is the freeware Lightworks that offers the most functions and editing tools. Even commercial movies have been cut and produced with that software; however it is not especially designed for beginners, so it requires time to get familiar with the production workflow. A more intuitive way and, therefore, more appropriate for beginners is the Windows Movie Maker (last built version is No. 12). It does support most of the latest video formats and has also built-in effects to make transitions and/or color effects and animated titles. It also supports most picture formats so that the producer can combine still and moving pictures in the project. Background sound or speech can be added and mixed.

- $\quad$ Screen-recording tools have become very popular as it is very easy to make engaging tutorials or presentations of what is happening on the monitor. The freeware tools Camstudio, Jing and AutoScreenrecorder offer the general possibility to record the screen but do also include restrictions which can be watermarks, a limited time for recordings or not supported audio recordings along with the screen recording. Also, the choice of output formats is limited in freeware tools.

- Two market leaders offer a professional tool that combines the above mentioned types of recording: Adobe Captivate, and Camtasia Studio. Camtasia Studio lets the user create professional screen recordings; you can include other media like pictures, movies or sound. The footage can be arranged in multi-track layers, with additional zoom or pan effects as well as highlighting options you can increase the professional look of the production. Below are given some examples of employing Camtasia Studio (ver. 7) in teaching students ECDIS simulator basis. Thus, Figures 3,4 , and 5 show some examples of using call-outs and zoom or pan effects in teaching students ECDIS (Electronic Chart Display and Information System) basis using Transas NAVI Sailor 4000 demo version simulator (Bauk et al., 2013b).

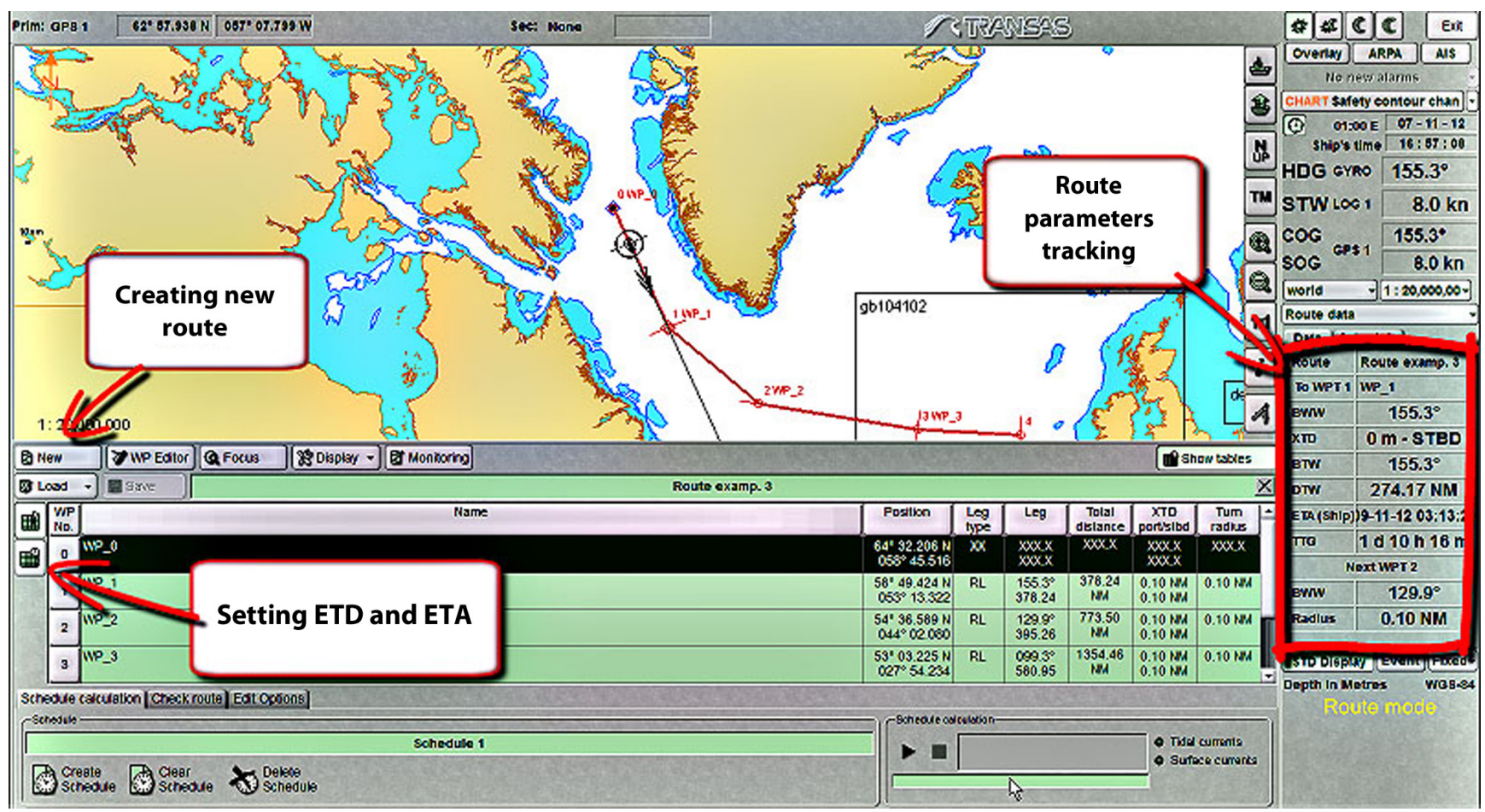

Figure 3.

Call-outs for route planning and scheduling in graphical mode. 


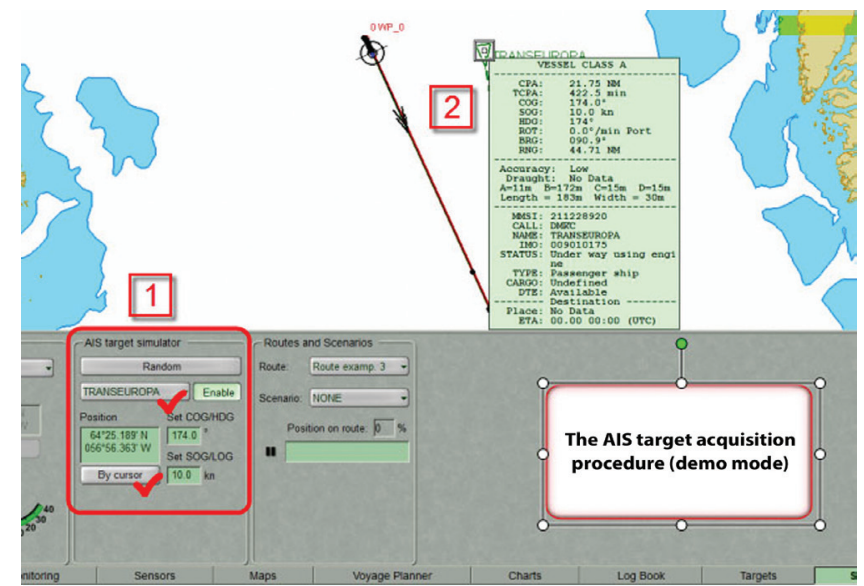

Figure 4.

Call-outs and zoom-n-pan effects for explanation of AIS target acquisition.

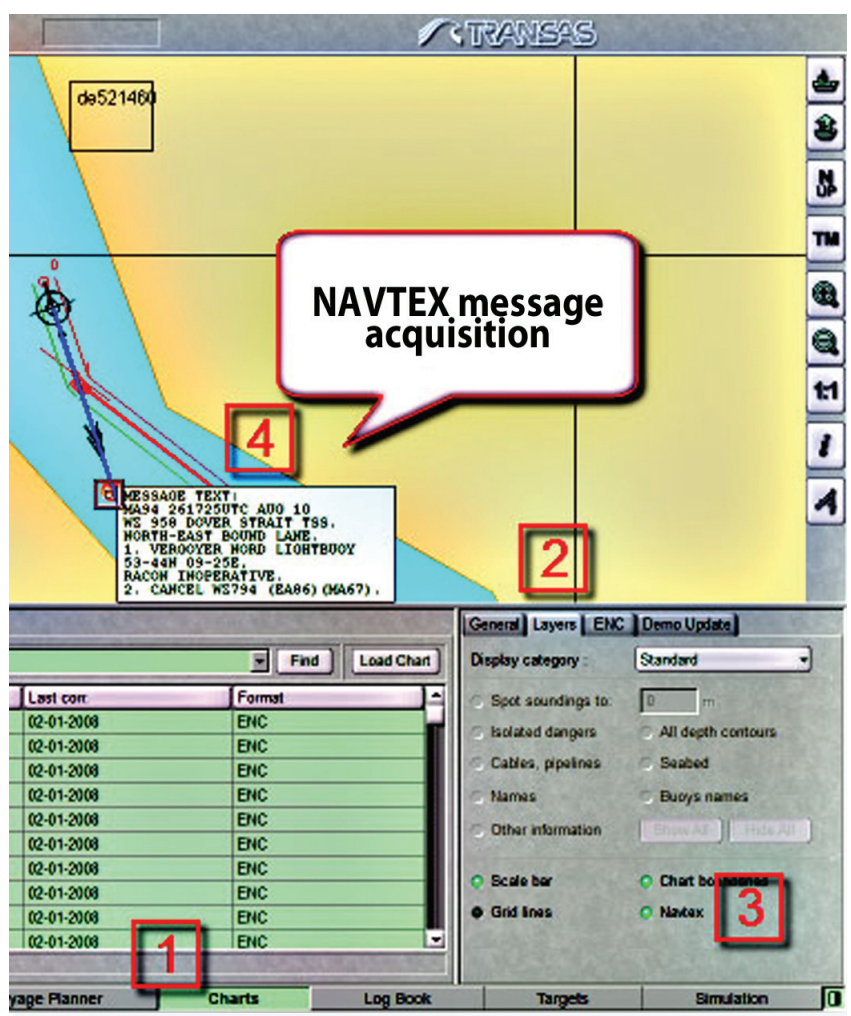

Figure 5.

Call-outs and zoom-n-pan effects for explanation of NAVTEX message acquisition.

\section{CONCLUSIONS}

All previously mentioned efforts in the introduction and development of e-learning resources at the FMS should improve the overall educational quality standards at MHETs in the Region. However, the need for greater investment in seafarers' higher education ( $\mathrm{HE}$ ) in terms of personnel and infrastructure is indisputable. The networking is also very important, and not "networking just for the sake of networking", but a real one is necessary, based on professional cooperation (on the EU level) among the MHET institutions through more intensive exchanges of teachers and students for the sake of mutual enrichment of knowledge and implementation of joint projects. It is necessary to establish permanent connections with the maritime industry, e.g. shipping companies interested in providing practical training on board ships as well. The national legislation has to be modernized in the sphere of higher education in terms of recognition and proper interpretation and implementation of the STCW (Standards of Training, Certification and Watch-keeping) requirements in terms of a faster deployment of virtual learning as a supplement to the traditional education and training of the seafarers. The newest STCW Code amendments concern and recommend: the introduction of modern training methodology including distance learning and web-based learning in seafarers' knowledge acquisition and upgrading. Within this context, sight should not be lost of the fact that STCW Convention itself calls for a proper education - as the foundation of successful training and acquiring competencies (see for more information "The Manila Amendments" - Chapter II, Section B-II/1, Paragraph 14, 2010). It is to be expected that at least some of these recommendations should be shortly considered and accepted by the responsible HE bodies.

REFERENCES

Adolf K.Y. Ng,A. K. Y., Koo, A. C. and Ho, J. W. C., (2009), The motivations and added values of embarking on postgraduate professional education: Evidences from the maritime industry. Transport Policy, 16(5), pp. 251-258.

Bauk S., Dlabač T. and Pekić Ž., (2012), Implementing E-learning Modes to the Students and Seafarers Education, Faculty of Maritime Studies in Kotor Case Study. Proc. 4th International Maritime Science Conference - IMSC, Solin, Croatia, June 1617, Faculty of Maritime Studies in Split, pp. 247-255.

Bauk S., Kopp M., and Avramovic Z., (2013a), A Case Study on Introducing E-learning into Seafarers'Education, JITA - Journal of Information Technology and Applications, 3(1), pp. 34-42.

Bauk S. and Radlinger R., (2013b), Inciting the Development of Engaging Screencasts in Teaching ECDIS. Proc. 10th Jubilee International Conference - TransNav - On Marine Navigation and Safety of Sea Transportation, 19-21 June, Gdynia, Poland. 
Bauk S., Šekularac-Ivošević S. and Jolić N., (2012), Seaport positioning supported by the combination of some quantitative and qualitative approaches, accepted for publishing in Transport.

Buzađija, N., (2011), The Way of Students' Efficiency Improvement in Knowledge Acquisition and Transfer Knowledge Model in Clarolina CMS, JITA - Journal of Information Technology and Applications, 1(2), pp. 127-135.

Fletcher S., Dodds W., (2003), The use of a virtual learning environment to enhance ICM capacity building, Marine Policy, 27(3), pp. 241-24.,

http://dx.doi.org/10.1016/S0308-597X(03)00003-4

Hanzu-Pazara R., Arsenie P. and Hanzu-Pazara L., (2010), Higher Performance in Maritime Education Through Better Trained Lecturers, TransNav - International Journal on Marine Navigation and Safety of Sea Transport, 4(1), pp. 87-93.

Kadioglu M., (2008), Information and Communication Technology (ICT) Training Application for MET Institutions, TransNav - International Journal on Marine Navigation and Safety of Sea Transport, 2(1), pp. 111-116.

Paechter M., Maier B. and Macher D., (2010), Students' expectations of, and experiences in e-learning: Their relation to learning achievements and course satisfaction, Computers \& Education, 54(1), pp. 222-229.
Pekić, Ž., (2011), Windows Mobile Application as Support for E-learning in Education, Proc. 6th International Symposium: Ports and Waterways (POWA), 12 October, Zagreb, Croatia (CD issue).

Shee D.Y., Wang Y.-S., (2008), Multi-criteria evaluation of the web-based e-learning system: A methodology based on learner satisfaction and its applications, Computers \& Education, 50(3), pp. 894-905.

Wang Y.-S., (2003), Assessment of learner satisfaction with asynchronous electronic learning system, Information \& Management, 41(1), pp. 75-86.,

http://dx.doi.org/10.1016/S0378-7206(03)00028-4

Best Free Audio Editing Software, available at: http://www.techsupportalert.com/ best-free-audio-editing-software.htm, [accessed January 2013.].

Best Free Video Editing Software, available at: http://webseasoning.com/ technology/best-free-windows-video-editing-software/1079/\#.UP_kph1bbUd, [accessed January 2013.].

Enhancing the quality of distance learning at Western Balkan higher education institutions,Tempus project report, available at: http://www.dlweb.kg.ac.rs, [accessed January, 2013.] 